\title{
Tobacco Use and its Correlates among Youth in a Northern Urban City of India
}

\author{
Devender Kumar ${ }^{1}$, Anupam Parashar ${ }^{2}$, Anita Thakur ${ }^{3}$ \\ ${ }^{1}$ Resident Doctor, Department of Community Medicine, IGMC Shimla \\ ${ }^{2}$ Professor, Department of Community Medicine, IGMC Shimla \\ ${ }^{3}$ Associate Professor, Department of Community Medicine, IGMC Shimla
}

\begin{abstract}
Introduction: Tobacco use is a widespread practice in India and is often considered socially and culturally acceptable especially in Himachal Pradesh. It is related to various health problems (cancers, NCDs etc.) and a number of international and national agencies have been working together for its control. Adolescents and young adults are assumed to be the most vulnerable age group to practice this behaviour and adopt it in their life style. This study aims to determine tobacco use and its correlates in this section of population in the Shimla city of Himachal Pradesh. Methods: A house to house community survey was done to determine tobacco use and other NCDs risk factors using Indian adaptation of WHO STEPs questionnaire developed by ICMR. Multi stage sampling is done to select participants of the age group of 15 to 24 years in the municipal corporation area of City. Data analysis was performed using Microsoft excel and Epi Info-7 software. Results: Total 603 participants (308 female and 295 male) were studied. $30.51 \%$ (C.I. 26.8934.39) had used tobacco product in any form in last one year. 18.08\% (C.I. 15.13 - 21.43) had been exposed to second hand smoke. $20.23 \%$ of participants were smoking tobacco products while $3.15 \%$ were using smokeless tobacco products daily. Smoking was found significantly associated with male gender, occupation and educational level. Smoking was associated with concurrent use of alcohol and insufficient physical activities. Conclusion: Tobacco use (especially in the form of Smoking as well as Second hand smoke) was found high. Tobacco control programmes therefore, remain important health issues.
\end{abstract}

Keywords: Tobacco use, Smoking, Second hand smoke, Tobacco control, Youth

\section{Introduction}

According to the WHO tobacco use is the leading cause of preventable death, and is estimated to kill more than 6 million people globally each year, both from direct use and second hand smoke. By 2020, this number will increase to 7.5 million, accounting for $10 \%$ of all deaths. Smoking alone is estimated to cause $71 \%$ of lung cancers, $42 \%$ of chronic respiratory diseases and nearly $10 \%$ of cardiovascular diseases. ${ }^{[1]}$ By 2030, the number of tobacco-related deaths could reach 8 million a year, if current trends continue; and an astonishing $80 \%$ of these premature deaths will be in lowand middle-income countries. ${ }^{[2.3 .4]}$ Majority of people start tobacco use at very young age and adopt it as behaviour in their life style. Approximately 100,000 children start smoking every day and if this pattern continued, it would kill 250 million of today's children. $47 \%$ of boys and $13 \%$ of girls have experimented with smoking in China, which consume $>30 \%$ of all cigarettes. ${ }^{[5,6,7,8]}$

In India the tobacco-attributable deaths currently range between 800,000 and 900,000 per year. ${ }^{[9]}$ The current use of any tobacco product among children varies from $3.3 \%$ to as high as $62.8 \%$ in different regions of country. ${ }^{[10]}$

WHO in collaboration with a number of national and international agencies is emphasizing on protecting young population from tobacco use, who are more likely to quit the habit in time before further harm. Number of initiatives has been taken throughout the country in the line of WHO FCTC (framework for convection of tobacco control). Shimla, a northern urban city of India is among the earliest in country to be declared as smoke free and has now been implementing tobacco control legislations for almost a decade. ${ }^{[11,12,13]}$ This community based cross sectional study was conducted to assess the current magnitude of problem by determining the prevalence of tobacco use and its correlates in young section of population in the Shimla city of Himachal Pradesh.

\section{Methodology}

Study area: This study was conducted among the youth of municipal corporation area of Shimla City that lies in the north-western ranges of the Himalayas and is located at $31.61^{\circ} \mathrm{N} 77.10^{\circ} \mathrm{E}$ with an average altitude of 2397.59 meters (7866.10 ft) above mean sea level. Population in municipal corporation area of is 169,758 as per 2011 census and is distributed in 25 different wards..$^{[14,15]}$

Study Population: The study was conducted among youth population between the age group 15 years to 24 years. Age limit is chosen as 15-24 years based upon WHO guideline for classifying youth. Selected population was divided into two groups as behaviour changes are initiated in younger age group (15-19 years) and long term decisions are taken by age $20-24$ years.

Study Design: It was a community based cross sectional study.

Sampling size: A total of 603 participants were included for study. This sample size was sufficient enough to determine prevalence of tobacco use and its correlate in study population considering expected outcome in the range of 20$30 \%, 95 \%$ confident interval and design effect of 1.5 . 


\section{International Journal of Science and Research (IJSR) ISSN (Online): 2319-7064 \\ Index Copernicus Value (2013): 6.14 | Impact Factor (2014): 5.611}

Sampling: Multistage sampling was used to select eligible individuals from the selected area as study units. Five wards were selected randomly from urban area for the study and each ward was divided into four zones i.e. North, South, East and West zone with approximately equal population. A household was selected randomly in the centre of selected zone which provided the first study subject. This was followed by consecutive sampling for selecting further households and individuals. In case no eligible candidate is found for enrolment in the study, we moved to next household until desired sample size is achieved. In case two or more eligible candidates were available in same household only one of them was selected randomly.

Inclusion criteria: Population in between 15-24 years who consented to participate was included in the study.

\section{Exclusion Criteria}

1) Those did not consent to participate.

2) Those who were suffering from serious illness, bed ridden/debilitating, psychiatric condition (were not in condition to participate in the study).

3) Pregnant women

Study period: One calendar year i.e. June 2014 through May 2015.

Data collection: The protocol developed by the WHO STEPS program was adopted. Information on sociodemographic variables and behavioural NCD risk factors (tobacco use, alcohol use, physical activity and diet) was collected using Indian adaptation of WHO STEPs questionnaire developed by ICMR in the local language. Clinical measurements Height, weight and blood pressure were measured using standardized instruments and protocols.

Ethical aspects: Prior permission was taken from institute ethical committee and informed consent was taken from each participant (Consent of parents or guardians was taken in case the participant is below the age of 18 years) after explaining the full purpose of the study. Participants were fully assured regarding the confidentiality and anonymity of the information provided by them.

Data analysis: The data collected was entered into excel sheet. Epi info 7 was used to find out percentages, means, standard deviation and confidence interval of various quantitative variables. Non parametric test of significance were applied to test the association between categorical variables.

\section{Results}

Total of 603 youth was studied that include 295 (48.92\%) male and $308(51.08 \%)$ female. Mean age of participants was 19.82 ( $\mathrm{SD} \pm 2.88$ ) years. Majority of the participants were students $(59.03 \%)$ and were never married (96.68\%). Most of the participants had either completed secondary school education or were pursuing higher education. (Table: 1)

Table 1: Demographic profile of participants

\begin{tabular}{|c|c|c|c|}
\hline \multicolumn{4}{|c|}{ AGE GROUP DISTRIBUTION } \\
\hline Age group (years) & Frequency & Percentage (\%) & Cumulative (\%) \\
\hline $15-19$ & 336 & 55.72 & 55.72 \\
\hline $20-24$ & 267 & 44.28 & 100 \\
\hline Total & 603 & 100 & 100 \\
\hline \multicolumn{4}{|c|}{ GENDER DISTRIBUTION } \\
\hline Male & 295 & 48.92 & 48.92 \\
\hline Female & 308 & 51.08 & 100 \\
\hline Total & 603 & 100 & 100 \\
\hline \multicolumn{4}{|c|}{ DISTRIBUTION BY MARITAL STATUS } \\
\hline Married & 20 & 3.32 & 3.32 \\
\hline Never Married & 583 & 96.68 & 100 \\
\hline Total & 603 & 100 & 100 \\
\hline \multicolumn{4}{|c|}{ DISTRIBUTION BY OCCUPATION } \\
\hline Student & 356 & 59.03 & 59.03 \\
\hline Professional/Big business & 5 & 0.82 & 59.85 \\
\hline Clerical/Medium business & 26 & 4.32 & 64.17 \\
\hline Agriculture/Self-employed & 39 & 6.47 & 70.64 \\
\hline Household \& domestic work & 9 & 1.49 & 72.13 \\
\hline Services & 15 & 2.49 & 74.62 \\
\hline Skilled manual & 70 & 11.61 & 86.23 \\
\hline Unskilled manual & 46 & 7.63 & 93.86 \\
\hline Do not work & 37 & 6.14 & 100 \\
\hline Total & 603 & 100 & 100 \\
\hline \multicolumn{4}{|c|}{ DISTRIBUTION BY EDUCATION LEVEL } \\
\hline Primary education & 6 & 0.99 & 0.99 \\
\hline High School & 106 & 17.57 & 18.56 \\
\hline Secondary School & 236 & 39.13 & 57.63 \\
\hline Graduate & 215 & 35.65 & 93.28 \\
\hline Post graduate/masters & 40 & 6.62 & 100 \\
\hline Total & 603 & 100 & 100 \\
\hline
\end{tabular}




\section{International Journal of Science and Research (IJSR) \\ ISSN (Online): 2319-7064 \\ Index Copernicus Value (2013): 6.14 | Impact Factor (2014): 5.611}

$30.51 \%$ (C.I. 26.89 - 34.39\%) of the participants had consumed tobacco product in any form i.e. smoking bidis cigarette etc. or consuming smokeless tobacco products like gutkha, jarda, khaini etc in last one year. Majority of them i.e. $87.5 \%$ are though cigarette smokers. $20.23 \%$ of participants were smoking tobacco products while $3.15 \%$ were using smokeless tobacco products daily. 109 i.e. $18.08 \%$ (C.I. 15.13 - 21.43\%) of the participants were exposed to second hand or environmental smoke at the time of study. (Table 2)

Table 2: Prevalence of tobacco use and its pattern among study participants

\begin{tabular}{|c|c|c|c|}
\hline \multicolumn{2}{|c|}{ Tobacco use } & Frequency $(n-603)$ & Percentage (95\% C.I.) \\
\hline $\begin{array}{c}\text { Consumed tobacco product in any } \\
\text { form in last one year }\end{array}$ & Yes & $184^{*}$ & $30.51 \%(26.89-34.39)$ \\
\cline { 2 - 4 } & No & 419 & $69.49 \%(65.61-73.11)$ \\
\hline Smoking tobacco products daily & 122 & $20.23 \%(17.14-23.71)$ \\
\hline Smoking tobacco products but not daily & 57 & $9.45 \%(7.29-12.14)$ \\
\hline Exposed to Second Hand Smoke & 109 & $18.08 \%(15.13-21.43)$ \\
\hline Used Smokeless tobacco product in past & 54 & $8.96 \%(6.86-11.59)$ \\
\hline Using Smokeless tobacco product daily & 19 & $3.15 \%(1.94-4.97)$ \\
\hline \multicolumn{2}{|r}{} \\
\hline
\end{tabular}

Mean age of starting tobacco product use was found to be 16.79 $\mathrm{SD} \pm 1.41$ years while average number of cigarette smoked per day were $5.91 \mathrm{SD} \pm 2.88$. Tobacco consumption was seen almost similar in two age groups studied while consumption was significantly higher among males (50.16\%). Tobacco abuses among students were $17.41 \%$ which was significantly lower than the participants who are engaged in some other occupation (49.39\%). 35.58\% of the participants with highest education (graduates or post graduates) were found to consuming tobacco product in any of form. (Table: 3 )

Table 3: Socio demographic pattern of tobacco consumption among the participants

\begin{tabular}{|c|c|c|c|c|}
\hline & Tobacco user (n-184) & Non-user (n- 419) & Total & $\mathrm{P}$ value \\
\hline \multicolumn{5}{|l|}{ Age group } \\
\hline $15-19$ years & $102(30.35)$ & $234(69.65)$ & 336 & \multirow[b]{2}{*}{0.9951} \\
\hline $20-24$ years & $82(30.71)$ & $185(69.29)$ & 267 & \\
\hline \multicolumn{4}{|l|}{ Gender } & \multirow{3}{*}{$<0.0000001$} \\
\hline Male & $148(50.16)$ & $147(49.84)$ & 295 & \\
\hline Female & $36(11.68)$ & $272(88.32)$ & 308 & \\
\hline \multicolumn{4}{|l|}{ Occupation } & \multirow{3}{*}{$<0.0000001$} \\
\hline Student & $62(17.41)$ & $294(82.59)$ & 356 & \\
\hline Other occupation & $122(49.39)$ & $125(50.61)$ & 247 & \\
\hline \multicolumn{4}{|l|}{ Highest education } & \multirow{5}{*}{0.02} \\
\hline Primary education & $3(50)$ & $3(50)$ & 6 & \\
\hline High school & $16(15.09)$ & $90(84.91)$ & 106 & \\
\hline Secondary school & $74(31.35)$ & $162(68.65)$ & 236 & \\
\hline Higher education & $91(35.58)$ & $164(64.42)$ & 255 & \\
\hline
\end{tabular}

Smoking was found to be associated with other risk factors for non-communicable disease like raised blood pressure and consumption of alcohol. 16.84\% of the smoker had raised blood pressure as compare to $3.34 \%$ in non-smoker which were significantly higher with an odds ratio of 5.86 (C.I. $3.03-11.31$ ). Similarly odds of smoker to be alcoholic were significantly higher than those who did not smoke. Also significant association was found between smoking and physical inactivity \& smoking and nutritional status of participants. 


\section{International Journal of Science and Research (IJSR) \\ ISSN (Online): 2319-7064}

Index Copernicus Value (2013): 6.14 | Impact Factor (2014): 5.611

Table 4: Association of smoking with other risk factors for non communicable diseases

\begin{tabular}{|c|c|c|c|}
\hline \multicolumn{4}{|c|}{ Association with blood pressure. } \\
\hline & Raised Blood pressure* & Normotensive & \\
\hline Smoker (184) & $31(16.84 \%)$ & 153 & \multirow{3}{*}{$\begin{array}{l}\text { Odds ratio }=5.86(\text { C.I. } 3.03-11.31) \\
\text { Risk ratio }=5.04 \text { (C.I. } 2.74-9.25) \\
\text { P value }<0.0000001\end{array}$} \\
\hline Non-smoker (419) & $14(3.34 \%)$ & 405 & \\
\hline Total & 45 & 558 & \\
\hline \multicolumn{4}{|c|}{ Association with use of alcohol. } \\
\hline & Alcoholic** & Non alcoholic & \multirow{4}{*}{$\begin{array}{l}\text { Odds ratio }=33.89 \text { (C.I. } 20.9-54.9) \\
\text { Risk ratio }=9.04 \text { (C.I. } 6.51-12.55) \\
\mathrm{P} \text { value }<0.0000001\end{array}$} \\
\hline Smoker (184) & $139(75.54 \%)$ & 45 & \\
\hline Non-smoker (419) & $35(8.35 \%)$ & 384 & \\
\hline Total & 174 & 429 & \\
\hline \multicolumn{4}{|c|}{ Association with physical activity. } \\
\hline & No regular physical activity & Regular physical activity*** & \multirow{4}{*}{$\begin{array}{l}\text { Odds ratio }=1.61(\text { C.I. } 1.04-2.4) \\
\text { Risk ratio }=1.11(\text { C.I. } 1.06-1.21) \\
P \text { value }-0.0 .04\end{array}$} \\
\hline Smoker (184) & $151(82.06 \%)$ & 33 & \\
\hline Non-smoker (419) & $310(73.98 \%)$ & 109 & \\
\hline Total & 461 & 142 & \\
\hline \multicolumn{4}{|c|}{ Association with nutritional status. } \\
\hline & Overweight / obese & Normal weight/underweight & \multirow{4}{*}{$\begin{array}{l}\text { Odds ratio }=3.73 \text { (C.I. } 2.33-6.25) \\
\text { Risk ratio }=3.14 \text { (C.I. } 2.01-4.90) \\
\text { P value }-0.000000542\end{array}$} \\
\hline Smoker (184) & $40(21.73 \%)$ & 144 & \\
\hline Non-smoker (419) & $29(6.92 \%)$ & 390 & \\
\hline Total & 69 & 534 & \\
\hline \multicolumn{4}{|c|}{$\begin{array}{l}\text { *raised blood pressure includes hypertension, pre-hypertension \& isolated systolic hypertension. } \\
* * \text { has been regularly using alcohol for last one year. } \\
* * * \text { involved in work or recreational activities that are of moderate intensity. }\end{array}$} \\
\hline
\end{tabular}

\section{Discussion}

India is a country of diverse cultures and multiple religions. Therefore the prevalence of tobacco use, which is also based on religious and cultural beliefs, is also variable. Himachal is the region where tobacco use has been acceptable for years. Shimla city being the Capital of Himachal and a well known tourist destination give enough exposure to its youth population regarding tobacco use. And also this age group as such has been considered as vulnerable for new experimentation. All these factors provide an enabling environment for our young generation to indulge in the habit of tobacco use that slowly traps them into the dependency.

The prevalence of tobacco use among school students in different States of India has been reported to vary from 1.9\% (Delhi) to $75.3 \%$ (Mizoram). ${ }^{[16,17,18,19,20,21,22,23]}$ Prevalence of current tobacco use among student was found $17.41 \%$ in the present study which is much higher than the $4.9 \%$ reported by GYTS in Himachal Pradesh. ${ }^{[2]}$ Overall Prevalence of current tobacco use was found $30.51 \%$ (majority i.e. $87.5 \%$ being the cigarette smokers). Prevalence of current tobacco use among male was $50.16 \%$ and in comparison to $11.68 \%$ in female. In a similar study from Haryana, prevalence in urban and urban slum area varied from 35 to $48 \%$ among male and 3 to $11 \%$ among female. ${ }^{[25]}$ High prevalence found in these study indicate alarming rise in the trend of tobacco use in the city and reflect poor impact of tobacco control initiatives and efforts from different government and nongovernmental agencies. This population should form the core that should be focussed in near future for tobacco control strategies.

$20.23 \%$ of participants were smoking tobacco products daily in the form of cigarette or bidi.

$3.15 \%$ were using smokeless tobacco products like gutkha, khaini etc. daily. Use of smokeless tobacco product was found less in comparison to what was estimated by GYTS.
This may be the impact of the legislative ban on the sale of smokeless tobacco products in the state which make availability of these products more difficult but not impossible.

Smoking and smokeless tobacco use are initiated and established primarily during adolescence worldwide. Mean age of initiation was found to be 16.79 in current study. In different study from India starting age ranges from 8 to 15 years. ${ }^{[26,27,28]}$ The majority of the tobacco users worldwide have reportedly first tried tobacco prior to age 18 , some starting as young as 10 years. ${ }^{[29.30]}$ This consistent finding again advocates in itself the importance of intervention at very early stage of life.

Exposure to second hand smoke (SHS) causes an estimated $5 \%$ of the global burden of disease, slightly higher than the burden from direct use of tobacco. ${ }^{[31]} 18.08 \%$ of the participants were exposed to second hand or environmental tobacco smoke in current study. Globally, about one third of adults are regularly exposed to second-hand tobacco smoke. [ ${ }^{32]}$

As per the GATS 2009 reports, the proportion of adults exposed to SHS ranges from $29 \%$ in public places to $50 \%$ at homes in India. Similarly, according to findings of GYTS (2007-2009), large proportions of youth had been exposed to SHS both at homes and in public places in this region. ${ }^{[33]}$ Legislative control through COTPA may prove an effective measure to prevent people from SHS at public place but for preventing it at home we need more comprehensive approach of which education and awareness should be important part.

Tobacco use in this study was found associated with other risk factor for non-communicable disease which further raises the concerns regarding primary prevention of NCD. Simultaneous use of alcohol and tobacco use has been noticed from different study which make victim manifold vulnerable for NCDs. ${ }^{[34,35,36]}$ People crave nicotine more

\section{Volume 5 Issue 2, February 2016}




\section{International Journal of Science and Research (IJSR) \\ ISSN (Online): 2319-7064}

Index Copernicus Value (2013): 6.14 | Impact Factor (2014): 5.611

when they are drinking, and crave alcohol more when they are smoking. Nicotine dampens brain's response to alcohol means more alcohol is required to experience the same effect. It increases body's levels of stress hormones which reduces the pleasure smokers get from alcohol. ${ }^{[37]}$ So we need a social environment which strongly discourage both these habits and promote healthy physical activities and dietary habits at the time of behaviour development.

The study has provided useful information on the prevalence of tobacco use among the youth, their exposure to SHS and its association with other risk behaviour. Both these exposures together have a great bearing on the prevalence of tobacco associated diseases occurring later in adulthood. The significance of prevalence data on tobacco use in the youth is important both to assess tobacco as a risk factor and to institute control measures for prevention of those diseases. Also it will further encourage people to understand, find out and sort out various factors responsible for this social as well as medical problem.

Some potential limitations of our study include self-reported smoking and drinking status that is bound for systematic error. Details of factors responsible for tobacco use were not assessed as the questionnaire used in this study was designed for NCDs risk factor profile not particularly for tobacco consumption.

\section{References}

[1] Park K. Park's Textbook of Preventive Medicine. 21st edition. Jabalpur: m/s Banarsidas Bhanot; 2015. p. 335336.

[2] Frieden TR, Bloomberg MR. How to prevent 100 million deaths from tobacco. Lancet. May 19 2007;369(9574):1758-1761.

[3] Mathers CD, Loncar D. Projections of Global Mortality and Burden of Disease from 2002 to 2030. Available with

http://www.whoindia.org/LinkFiles/HSD_Resources_Pr ojections_of_Global_Mortality_and_Burden_of_Diseas e.pdf Accessed on 09/12/2015.

[4] Oberg M., Jaakkola M. S., Woodward A., Peruga A., Pruss-Ustun A. (2011). Worldwide burden of disease from exposure to second-hand smoke: a retrospective analysis of data from 192 countries. Lancet 377, 139146 10.1016/S0140-6736(10)61388-8.

[5] Jha P, Chaloupka FJ, Curbing the Epidemic: Governments and the Economics of Tobacco Control. Washington DC: The World Bank; 1999.

[6] Gostin LO. Global regulatory strategies for tobacco control. Jama. Nov 7 2007;298(17):2057-2059.

[7] Warren CW, Riley L, Asma S, Eriksen MP, Green L, Blanton C, Loo C, Batchelor S, Yach D. Tobacco use in youth: a surveillance report from the Global Youth Tobacco Survey Project. Vol. 78. Bulletin of World Health Organization; 2000. p. 868-876.

[8] Heishman SJ. Tobacco - the once and future addiction: editorial. Addiction. 2001;96:1389-1390. doi: 10.1046/j.1360-0443.2001.961013891.x.

[9] Crisis in India: Smoking Expected to Kill 1 Million People Annually by 2010 available with http://environment.about.com/od/healthenvironment/a/s moking_deaths.htm Accessed on 10/12/2015
[10] Reddy, K.S.; Gupta, P.C. Tobacco Control in India; Ministry of Health and Family Welfare,

[11] Government of India: New Delhi, India, 2004. Tobacco Free Initiatives in Himachal Pradesh http://www.hphealth.nic.in/pdf/2010CaseStudySmokeFr eeHimachal.pdf Accessed on 12/09/2015

[12] Himachal Pradesh declared first smoke-free state in country The Economic Time PTI Jul 2, 2013, 10.43PM IST available with http://articles.economictimes.indiatimes.com/2013-0702/news/40329048_1_himachal-pradesh-universitycompliance-cotpa Accessed on 10/12/2015

[13] Shimla declared fourth smoking-free city in India Zee news Last Updated: Sunday, October 3, 2010 - 09:57 available at http://zeenews.india.com/news/himachalpradesh/shimla-declared-fourth-smoking-free-city-inindia_659175.html Accessed on 20/12/2015

[14] Muncipal corporation Shimla geographical structure http://www.shimlamc.gov.in/page/Geographical.aspx Accessed on 10/09/2015

[15] Shimla District : Census 2011 data available with http://www.census2011.co.in/census/district/239shimla.html Accessed o 20/12/2015

[16]Kumar M, Poorni S, Ramachandran S. Tobacco use among school children in Chennai city, India. Indian J Cancer 2006;43:127-31.

[17] Bhojani UM, Chander SJ, Devadasan N. Tobacco use and related factors among pre-university students in a college in Bangalore, India. Natl Med $\mathrm{J}$ India 2009;22:294-7.

[18] Sinha DN, Gupta PC, Pednekar MS. Tobacco use among students in the eight north-eastern states of India. Indian J Cancer 2003;40:43-59.

[19] Singh V, Pal HR, Mehta M, Dwivedi SN, Kapil U. Pattern of tobacco use among school children in National Capital Territory (NCT). Indian J Pediatr 2007;74:1013-20.

[20] Kapil U, Goindi G, Singh V, Kaur S, Singh P. Consumption of tobacco, alcohol and betel leaf amongst school children in Delhi. Indian J Pediatr 2005;72:993.

[21] Pednekar MS, Gupta PC. Tobacco use among school students in Goa, India. Indian J Public Health 2004;48:147-52.

[22] Gajalakshmi V, Asma S, Warren CW. Tobacco survey among youth in south India. Asian Pac J Cancer Prev 2004;5:273-8.

[23] Kapoor SK, Anand K, Kumar G. Prevalence of tobacco use among school and college going adolescents of Haryana. Indian J Pediatr 1995;62:461-6.

[24] Jindal SK, Aggarwal AN, Gupta D, Kashyap S. Chaudhary D. Prevalence of Tobacco Use Among School Going Youth in North Indian States Indian J Chest Dis Allied Sci 2005;47:161-166.

[25] Gupta V, Yadav K, Anand K. Patterns of Tobacco Use Across Rural, Urban, and Urban-Slum Populations in a North Indian Community. Indian J Community Med. Apr 2010; 35(2): 245-251.

[26] Bhojani UM, Chander SJ, Devadasan N. Tobacco use and related factors among pre-university students in a college in Bangalore, India. Natl Med $\mathrm{J}$ India 2009;22:294-7.

[27] Chadda RK, Sengupta SN. Tobacco use by Indian adolescents. Tob Induc Dis 2002;1:111-9. 


\section{International Journal of Science and Research (IJSR) \\ ISSN (Online): 2319-7064}

Index Copernicus Value (2013): 6.14 | Impact Factor (2014): 5.611

[28] Kapil U, Goindi G, Singh V, Kaur S, Singh P. Consumption of tobacco, alcohol and betel leaf amongst school children in Delhi. Indian J Pediatr 2005;72:993.

[29] Reddy KS, Arora M. Tobacco use among children in India: A burgeoning epidemic. Indian Pediatr 2005;42:757-61.

[30] Ahmed NU, Ahmed NS, Semenya KA, Elzey JD, Larson C, Bennett CR, et al. Prevalence and correlates of initiation of smoking behavior among preteen black and white children. J Natl Med Assoc 2004;96:200-8.

[31] Singh RJ, Lal PG. Second-hand Smoke: A neglected public health challenge. Indian $J$ Public Health 2011;55:192-8.

[32] WHO Report on the Global Tobacco Epidemic 2009: Implementing smoke-free environments. Geneva: World Health Organization. 2009. Available from: http://www.who.int/tobacco/mpower/2009/en/. Accessed on 22/12/2015

[33] Singh RJ, Lal PG. Second-hand Smoke: A neglected public health challenge. Indian $J$ Public Health 2011;55:192-8.

[34] De Leon J, Rendon DM, Baca-Garcia E, Aizpuru F, Gonzalez-Pinto A, Anitua C, Diaz FJ. Association between smoking and alcohol use in the general population: stable and unstable odds ratios across two years in two different countries. Alcohol Alcohol. 2007 May-Jun;42(3):252-7.

[35] Morgen CS, Bové KB, Larsen KS, KjærSK, Morten. Association Between Smoking and the Risk of Heavy Drinking Among Young Women: A Prospective Study. Alcohol Alcohol. 2008;43(3):371-375.

[36] Kumar V, Nehra DK, Kumar P, Sunila, Gupta R. Prevalence and pattern of substance use -A study from de addiction centre. Delhi psychiatry journal 2013; 16:(1).

[37] So THAT'S why drinking and smoking go hand in hand: Nicotine dampens feel-good chemicals in the brain, making us crave alcohol. Available with http://www.dailymail.co.uk/health/article-

2373458/Drinking-smoking-hand-hand-recent-researchsuggests-Nicotine-dampens-feel-good-chemicals-brainmaking-crave-alcohol.html Accessed on 22/12/2015. 